\title{
Postoperative outcomes in distal hypospadias: a meta-analysis of the Mathieu and tubularized incised plate repair methods for development of urethrocutaneous fistula and urethral stricture
}

\author{
Hans Winberg ${ }^{1,2} \cdot$ Einar Arnbjörnsson ${ }^{1,2} \cdot$ Magnus Anderberg $^{1,2} \cdot$ Pernilla Stenström ${ }^{1,2}$
}

Accepted: 12 July 2019 / Published online: 1 August 2019

(c) The Author(s) 2019

\begin{abstract}
Purpose To compare the two major complications, namely postoperative urethrocutaneous fistula and urethral stricture, between the Mathieu and tubularized incised plate (TIP) repair methods for distal hypospadias.

Methods In this meta-analysis, electronic databases were searched for comparative studies on the two techniques. The Oxford Centre for Evidence-based Medicine Levels of Evidence was used to evaluate the included studies. The main outcome measure was the frequency of postoperative fistula and urethral stricture. RevMan 5.3 was used for statistical analyses, with $P<0.05$ indicating statistical significance.

Results A total of 17 studies, which included 1572 patients, met the inclusion criteria. The frequency of urethrocutaneous fistula did not differ between the Mathieu [115 (13\%)] and TIP [90 (13\%)] methods [odds ratio (OR) 1.1, 95\% confidence intervals (CI) $0.6-1.9 ; P=0.73)$ ]. Urethral stricture was less frequent after the Mathieu [15 (2\%)] method than after the TIP [37 (5\%)] method (OR 0.5, 95\% CI 0.3-0.8; $P<0.01$ ), even after the subgroup analysis of eight randomized controlled trials was included. Overall, the quality of the included studies was determined to be satisfactory. The levels of evidence on which this review was based ranged from $1 b$ to $2 b$ using the CEBM Levels of Evidence.

Conclusion Compared with TIP repair, Mathieu repair for hypospadias had a significantly lower risk for urethral stricture; however, the risk for urethrocutaneous fistula was similar.
\end{abstract}

Keywords Meta-analyses · Hypospadias repair · Mathieu (PBF) - Tubularized incised plate repairs (TIP) - Boys · Outcome $\cdot$ Urethrocutaneous fistula $\cdot$ Urethral stricture

\section{Introduction}

Electronic supplementary material The online version of this article (https://doi.org/10.1007/s00383-019-04523-z) contains supplementary material, which is available to authorized users.

Hans Winberg

winberghans@gmail.com

Einar Arnbjörnsson

einar.arnbjornsson@telia.com

Magnus Anderberg

magnus.anderberg@med.lu.se

Pernilla Stenström

pernilla.stenstrom@med.lu.se

1 Department of Pediatric Surgery, Skåne University Hospital, 22185 Lund, Sweden

2 Department of Clinical Sciences, Pediatrics, Lund University, Lund, Sweden
The widely practiced and established procedures to correct distal penile hypospadias are the Mathieu technique with a perimeatal-based flap and tubularized incised plate (TIP) urethroplasty. The Mathieu technique was first described in 1932 and has been mainly used for coronal and subcoronal hypospadias [1]. Tubularized incised plate urethroplasty was first described in 1994 and has been used to correct distal hypospadias [2, 3]. In both the Mathieu technique and TIP urethroplasty, the neourethra is tunneled into the glans to create a vertical meatus, with the aim of making the glans shape and external meatus appearance natural after repair [4]. For both methods, complication rates have been reported to be $2-13 \%$ [3-5]. The most common reported serious complications after hypospadias surgery are urethral stricture and urethrocutaneous fistula, both of which require surgical treatment. To date, there has been 
no consensus on the better choice between the Mathieu and TIP techniques, as well as on the short- and longterm outcomes of both procedures [5]. This meta-analysis aimed to compare the postoperative rates of urethrocutaneous fistula and urethral stricture between the Mathieu technique and TIP urethroplasty.

\section{Methods}

\section{Search strategies}

The meta-analysis was conducted following the PRISMA guidelines [6]. Using the keyword "hypospadias," all literature published from January 1990 to January 2019 was searched in PubMed, Embase, and Cochrane databases. The inclusion criteria were "hypospadias," "Mathieu," "tubularized incised plate repairs," "TIP," "Snodgrass," and "complications" data that could be obtained from the paper. Cases were included only if the complications were identified and described with clarity in the paper. Filters were set for articles in English and those that included different age groups (i.e., infants, children, and adolescents).

First, all the abstracts were screened; all the studies that reported postoperative complications as an outcome after the Mathieu and TIP techniques were considered to meet the inclusion criteria. Then, the full articles were retrieved. All the eligible abstracts and articles were assessed independently by HW and EA for inclusion in the meta-analysis.

\section{Inclusion criteria}

This study included all comparative studies who reported on urethrocutaneous fistula and urethral stricture after hypospadias repair by the two repair methods, the Mathieu and TIP techniques on boys younger than 18 years of age.

\section{Exclusion criteria}

This study excluded all non-original articles; those with cohorts smaller than ten patients; those with a greater than 10:1 ratio between the two techniques; those that lacked reports on the two complications studied; those that reported overlapping data; and those in previously published articles. To reduce the risk of modification of the methods that might have influenced the rate of complications, studies with time interval of greater than 20 years were excluded. Studies that included repeat operations were included when differentiating between repeat and primary interventions was not possible.

\section{Complications}

Complications were defined according to Clavien-Dindo [7]; studies with grade $3 \mathrm{~b}$ complications of urethrocutaneous fistula and urethral stricture that required reoperation under general anesthesia were included. The definition of stricture was subjectively decided by the surgeon/author or was objectively measured in correlation with the patients age or postoperative time. Complications, such as infections and wound dehiscence, as well as cosmetics, were excluded from the analyses.

\section{Data extraction}

The data extracted from the included articles were the study characteristics, such as authors, publication year, sample size, time span, surgical technique (Mathieu or TIP technique), and follow-up period, and patient characteristics, including age at surgery and degree of hypospadias. Specific information on the postoperative complications was collected and analyzed. In cases of uncertainty, events were not included.

\section{Quality assessment}

The level of evidence and publication type was classified according to the Oxford CEBM [8].

\section{Statistical analysis}

The Mantel-Haenszel method was used to calculate pooled odds ratio (OR) [9]. Dichotomous variables were analyzed by estimating the ORs with $95 \%$ confidence intervals (CIs). $P$ values $<0.05$ were considered statistically significant. The RevMan 5.3 statistical package was used to conduct the meta-analysis [10].

\section{Results}

A search for "hypospadias, Mathieu, TIP repair, and children" provided 110 studies, of which 17 were relevant for this study. A total of 110 abstracts were screened, of which 17 studies met the eligibility criteria. After collecting the information from the full text articles, all 17 studies fulfilled the criteria to be included in the final meta-analysis [11-27] (Fig. 1). Eight of the analyzed studies were RCTs [11, 15-17, 20-22, 24] (Table 1). All the included RCTs included comparisons between Mathieu and TIP. The overall CEBM criteria ranged from $1 b$ to $2 b$. Search for hypospadias and meta-analysis revealed seven publications, but none of those were relevant for this study. 
Fig. 1 Flowchart of the process to search for articles that compared the complications after hypospadias reconstruction using the Mathieu and TIP repair methods
Table 1 A summary of the studies included in this metaanalysis
17 studies included in qualitative synthesis and in quantitative synthesis (meta-analysis)

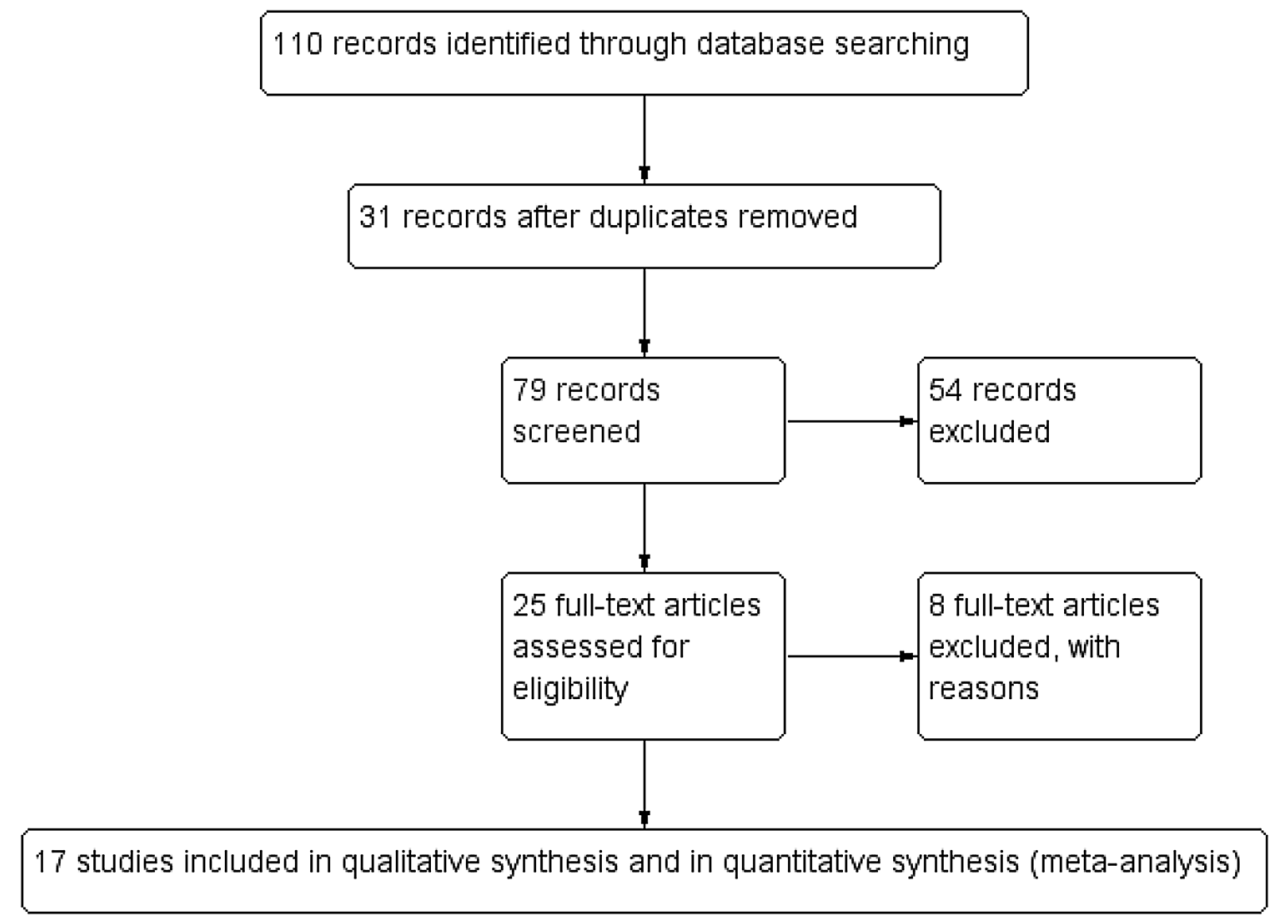

\begin{tabular}{|c|c|c|c|c|c|c|c|c|}
\hline \multirow[t]{2}{*}{ References } & \multirow[t]{2}{*}{ Year } & \multirow{2}{*}{$\begin{array}{l}\text { Level of } \\
\text { evidence }\end{array}$} & \multirow{2}{*}{$\begin{array}{l}\text { Mathieu } \\
n\end{array}$} & \multirow{2}{*}{$\begin{array}{l}\text { TIP } \\
n\end{array}$} & \multicolumn{2}{|l|}{ Mathieu } & \multicolumn{2}{|l|}{ TIP } \\
\hline & & & & & Fistulae & Stricture & Fistulae & Stricture \\
\hline Aminsharifi [11] & 2008 & $1 b^{\mathrm{a}}$ & 20 & 20 & $0(0 \%)$ & $0(0 \%)$ & $2(10 \%)$ & $5(25 \%)$ \\
\hline Anwar-ul-haq [12] & 2006 & $2 b^{b}$ & 45 & 45 & $7(16 \%)$ & $3(7 \%)$ & $3(7 \%)$ & $2(4 \%)$ \\
\hline Bae [13] & 2014 & $2 b$ & 13 & 25 & $1(8 \%)$ & $0(0 \%)$ & $6(24 \%)$ & $1(4 \%)$ \\
\hline Chrzan [14] & 2007 & $2 \mathrm{~b}$ & 25 & 26 & $1(4 \%)$ & $1(4 \%)$ & $17(65 \%)$ & $1(4 \%)$ \\
\hline Elganainy [15] & 2010 & $1 \mathrm{~b}$ & 64 & 37 & $5(8 \%)$ & $0(0 \%)$ & $3(8 \%)$ & $5(14 \%)$ \\
\hline Guo [16] & 2004 & $1 \mathrm{~b}$ & 43 & 36 & $11(26 \%)$ & $1(2 \%)$ & $3(8 \%)$ & $2(6 \%)$ \\
\hline Hamid [17] & 2014 & $1 b$ & 48 & 52 & $6(13 \%)$ & $4(8 \%)$ & $3(6 \%)$ & $3(6 \%)$ \\
\hline Imamoğlu [18] & 2003 & $2 b$ & 54 & 56 & $4(7 \%)$ & $2(4 \%)$ & $4(7 \%)$ & $5(9 \%)$ \\
\hline Karabulut [19] & 2008 & $2 b$ & 9 & 4 & $5(56 \%)$ & $0(0 \%)$ & $2(50 \%)$ & $1(25 \%)$ \\
\hline Moradi [20] & 2005 & $1 b$ & 18 & 15 & $1(6 \%)$ & $0(0 \%)$ & $2(13 \%)$ & $1(7 \%)$ \\
\hline Nezami [21] & 2010 & $1 \mathrm{~b}$ & 33 & 21 & $1(3 \%)$ & $0(0 \%)$ & $1(5 \%)$ & $1(5 \%)$ \\
\hline Oswald [22] & 2000 & $1 b$ & 30 & 30 & $2(7 \%)$ & $1(3 \%)$ & $0(0 \%)$ & $0(0 \%)$ \\
\hline Oztorun [23] & 2017 & $2 b$ & 331 & 161 & $38(11 \%)$ & $1(0 \%)$ & $23(14 \%)$ & $1(1 \%)$ \\
\hline Samore [24] & 2006 & $1 b$ & 10 & 10 & $2(20 \%)$ & $1(10 \%)$ & $2(20 \%)$ & $1(10 \%)$ \\
\hline Ugras [25] & 2006 & $2 b$ & 34 & 20 & $5(15 \%)$ & $0(0 \%)$ & $3(15 \%)$ & $1(5 \%)$ \\
\hline Winberg [26] & 2016 & $2 \mathrm{~b}$ & 69 & 73 & $24(35 \%)$ & $0(0 \%)$ & $10(14 \%)$ & $4(5 \%)$ \\
\hline \multirow[t]{2}{*}{ Yildiz [27] } & 2010 & $2 \mathrm{~b}$ & 16 & 79 & $2(13 \%)$ & $1(6 \%)$ & $6(8 \%)$ & $3(4 \%)$ \\
\hline & & Sum & 862 & 710 & 115 & 15 & 90 & 37 \\
\hline
\end{tabular}

TIP tubularized incised plate

${ }^{a}$ Randomized controlled trial (RCT)

${ }^{\mathrm{b}}$ Cohort study 


\section{Study characteristics}

A total of 1572 patients (range, 13-492 patients per study) were included in the meta-analysis. Of these, 862 (55\%) had undergone surgery with the Mathieu technique and $710(45 \%)$ with TIP technique. Some local variations in the surgical methods were noted during the data extraction, although the general principles of the methods were equal and allowed comparison. Data on age at surgery, weight, and indication for the hypospadias repair were not provided in detail in all the studies; therefore, these were not included in the current analysis. A summary of the characteristics of the included studies is shown in Table 1.

\section{Frequencies of fistula and stricture}

Overall, 259 of 1572 (16\%) boys developed complications of fistulas and urethral strictures that required reoperation. Specifically, these complications occurred in 130 of $862(15 \%)$ patients who underwent the Mathieu procedure and in 129 of $710(18 \%)$ patients who underwent the TIP procedure.

\section{Urethrocutaneous fistula}

In all the 17 studies, postoperative urethrocutaneous fistula was assessed in 1572 patients [11-27]. Fistula was the most common observed and reported complication in 13\% (205/1572) of all studies and was equally distributed between the Mathieu and TIP techniques (13\% each) without any significant difference between the two methods (Fig. 2). The frequency of postoperative fistula formation varied between 0 and $56 \%$ with Mathieu repair and between 0 and $65 \%$ with the TIP technique. Meta-analysis of the 17 studies revealed that the risk of fistula development after the Mathieu procedure did not significantly differ from that after the TIP procedure (OR 1.1, 95\% CI 0.6-1.8; $P=0.82$ ) (Fig. 2).

\section{Urethral stricture}

Urethral stricture was evaluated in all the 17 studies [11-27]. The risk for stricture complications was $0-10 \%$ after the Mathieu procedure and 0-25\% after the TIP procedure. In most reports, a clear definition of the urethral stricture was missing. After pooling the data of the 17 studies, the rate of urethral stricture appeared to be significantly lower after the Mathieu (2\%) than after TIP (5\%) (OR 0.5, 95\% CI 0.3-0.8; $P=0.004)$ (Fig. 3).

\section{Analysis of randomized controlled trials}

The methodological quality of the RCTs was analyzed. In both the overall and subgroup (RCTs) [11, 15-17, 20-22, 24] analyses, the rate of fistula did not differ between the two methods (Fig. 4), but the rate of stricture was significantly lower after the Mathieu than after the TIP technique $(P=0.02)$ (Fig. 5).

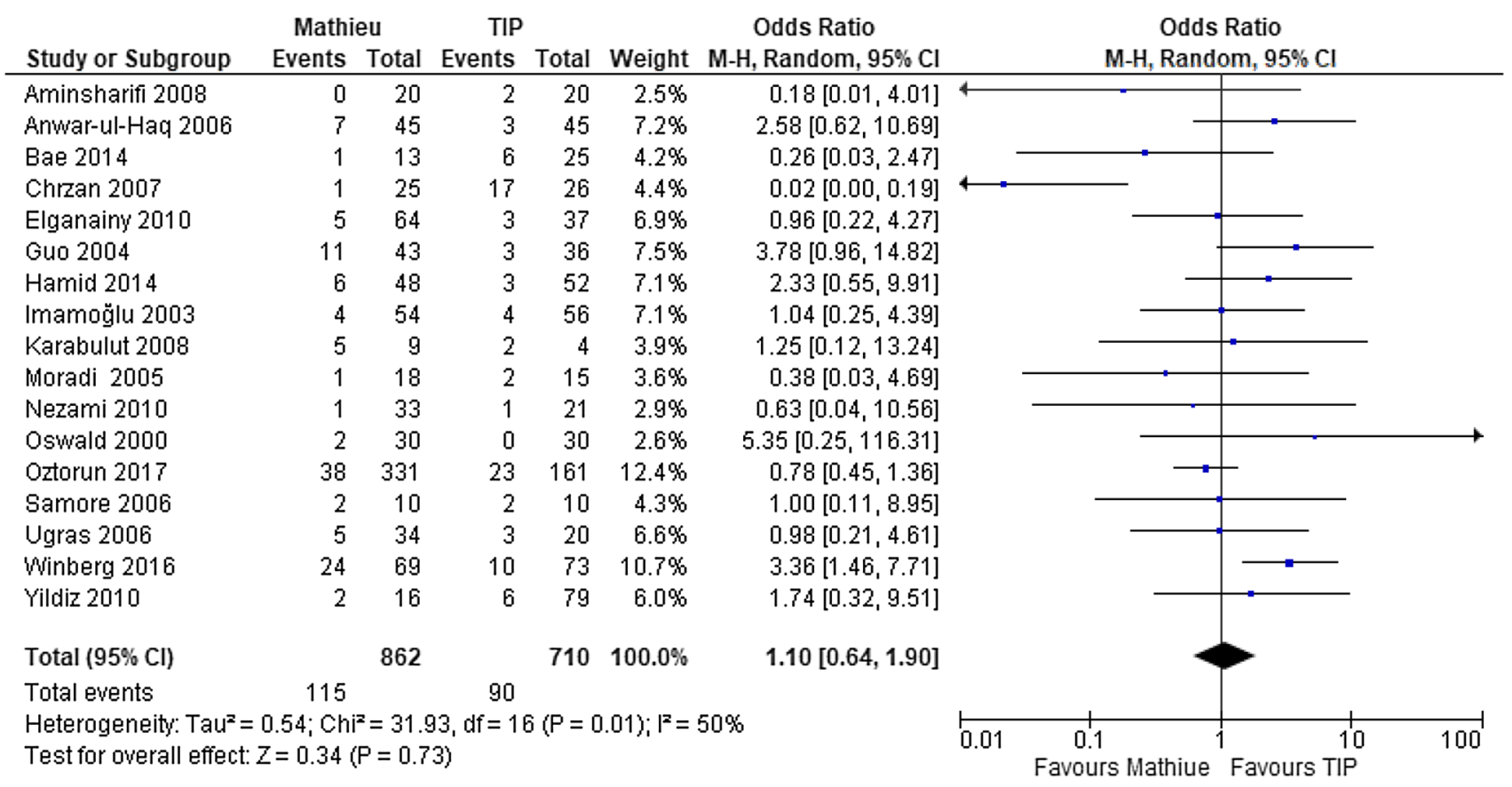

Fig. 2 Forest plot of the comparison between the Mathieu and TIP repair methods for hypospadias reconstruction, in terms of fistula formation 


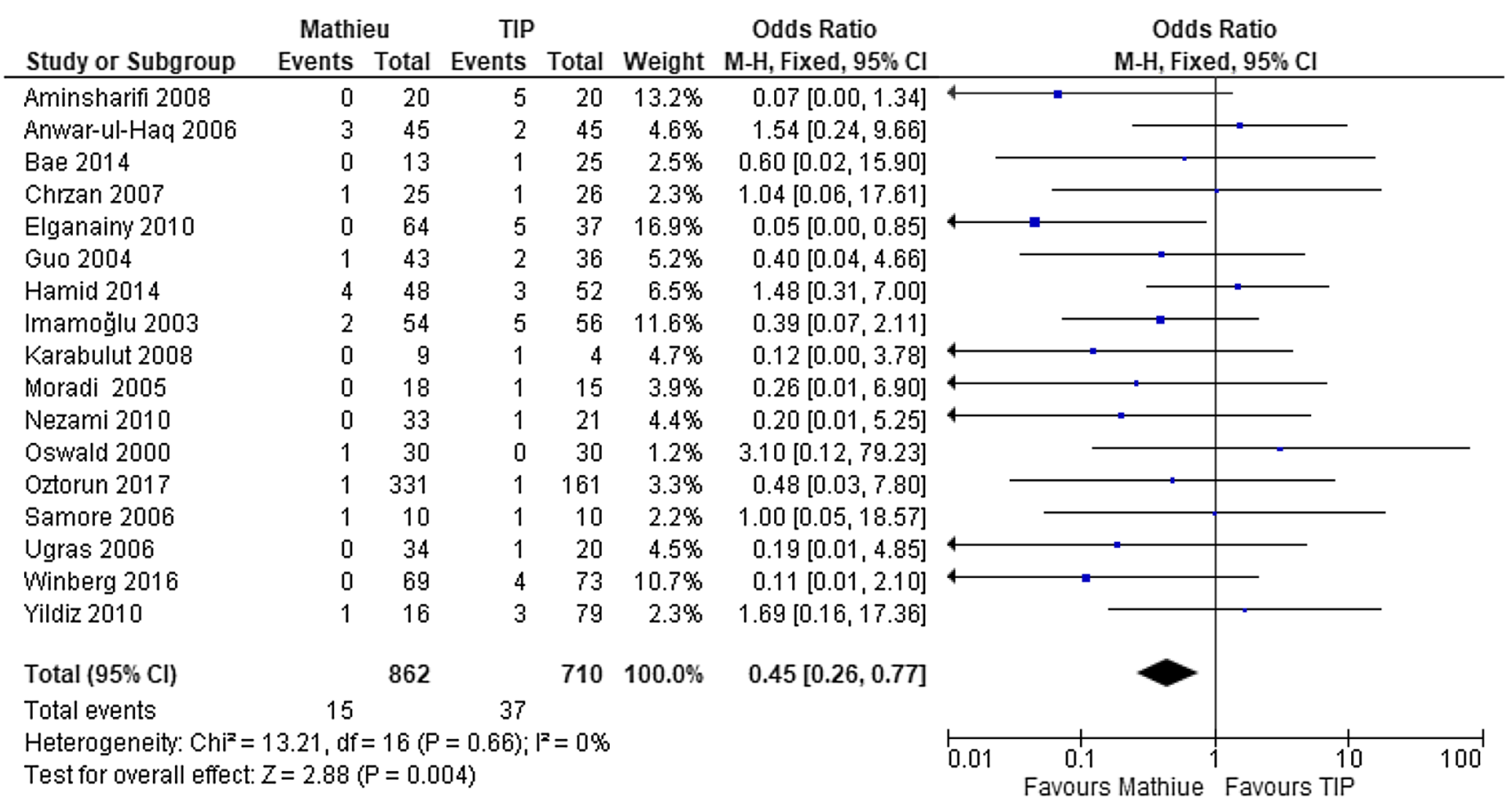

Fig. 3 Forest plot of the comparison between the Mathieu and TIP repair methods for hypospadias reconstruction, in terms of postoperative strictures

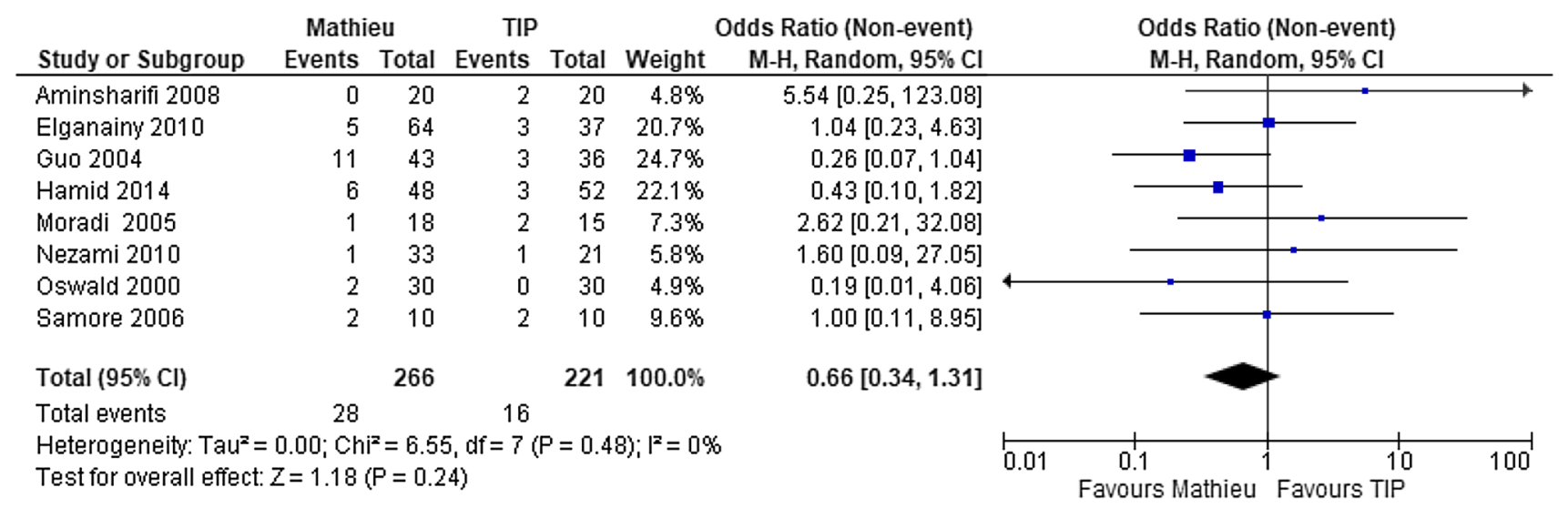

Fig. 4 Forest plot of the comparison between the Mathieu and TIP repair methods for hypospadias reconstruction, in terms of fistula formation among the RCTs

\section{Consistency}

The details of the surgical procedures varied in some of the analyzed studies. The Mathieu technique was sometimes slightly modified, and the coverage of the neourethra was performed by either a single-layer or double-layer technique. Furthermore, there were diverse variations in the size and material of the suture used for urethroplasty and glansplasty and in the size of the stent, if used, for urinary diversion. Excluding the three publications that contained some repeat procedures $[17,18,22]$ did not change the results on the absence of differences between the two methods in terms of urethrocutaneous fistulas and on the lower frequency of strictures after the Mathieu repair than after the TIP technique.

\section{Publication bias}

Possible publication bias was analyzed by reviewing the distribution of the results on funnel plot diagrams (Figures 6-9) 


\begin{tabular}{|c|c|c|c|c|c|c|c|c|c|}
\hline Study or Subgroup & \multicolumn{2}{|c|}{ Mathieu } & \multicolumn{2}{|c|}{ TIP } & \multicolumn{2}{|r|}{ Odds Ratio } & \multicolumn{3}{|c|}{$\begin{array}{c}\text { Odds Ratio } \\
\text { M-H, Fixed, } 95 \% \mathrm{Cl}\end{array}$} \\
\hline Aminsharifi 2008 & 0 & 20 & 5 & 20 & $24.7 \%$ & $0.07[0.00,1.34]$ & 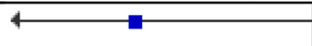 & T & \\
\hline Elganainy 2010 & 0 & 64 & 5 & 37 & $31.6 \%$ & $0.05[0.00,0.85]$ & $\longleftrightarrow$ & & \\
\hline Guo 2004 & 1 & 43 & 2 & 36 & $9.8 \%$ & $0.40[0.04,4.66]$ & & & \\
\hline Hamid 2014 & 4 & 48 & 3 & 52 & $12.1 \%$ & $1.48[0.31,7.00]$ & & & \\
\hline Moradi 2005 & 0 & 18 & 1 & 15 & $7.3 \%$ & $0.26[0.01,6.90]$ & $\leftarrow$ & & \\
\hline Nezami 2010 & 0 & 33 & 1 & 21 & $8.2 \%$ & $0.20[0.01,5.25]$ & $\longleftarrow$ & & \\
\hline Oswald 2000 & 1 & 30 & 0 & 30 & $2.2 \%$ & $3.10[0.12,79.23]$ & & & \\
\hline Samore 2006 & 1 & 10 & 1 & 10 & $4.1 \%$ & $1.00[0.05,18.57]$ & & & \\
\hline Total $(95 \% \mathrm{Cl})$ & & 266 & & 221 & $100.0 \%$ & $0.40[0.18,0.85]$ & & & \\
\hline Total events & 7 & & 18 & & & & & & \\
\hline $\begin{array}{l}\text { Heterogeneity: } \mathrm{Chi}^{2}= \\
\text { Test for overall effec }\end{array}$ & $\begin{array}{l}8.37, \mathrm{df}= \\
Z=2.360\end{array}$ & $\begin{array}{l}P(P= \\
P=0.0\end{array}$ & $\begin{array}{l}0.30) ; 1^{2}= \\
\text { 2) }\end{array}$ & $=16 \%$ & & & $\begin{array}{c}0.1 \\
\text { Favours Mathieu }\end{array}$ & $\begin{array}{l}10 \\
\text { Favours TIP }\end{array}$ & 100 \\
\hline
\end{tabular}

Fig. 5 Forest plot of the comparison between the Mathieu and TIP repair methods for hypospadias reconstruction, in terms of postoperative strictures among the RCTs

found in the supplementary material. The funnel plot figures demonstrated only some asymmetry, suggesting little evidence of publication bias.

\section{Discussion}

This meta-analysis was based on 17 reports that included 1572 patients. The level of evidence ranged from $1 \mathrm{~b}$ to $2 \mathrm{~b}$. Fistula was the most common (13\%) complication after hypospadias repairs and had a similar rate between the Mathieu and TIP techniques. Both techniques had low rates of postoperative complications, but the risk for urethral stricture was lower after the Mathieu than after TIP. Subgroup analysis of eight RCTs showed consistent results.

To our best knowledge, this was the first meta-analysis that showed significant differences in postoperative complications between the Mathieu and TIP techniques for hypospadias repair. Similar to this study, one systematic review (2012) and another meta-analysis (2013) showed that both the Mathieu and TIP repair methods had low rates of postoperative complications (2-15\%), and no significant difference was found overall $[5,28]$. A systematic review of studies published before 2010 concluded that both reconstruction techniques for distal hypospadias had low rates of postoperative complications, but it did not present a clear consensus on the ideal method [5]. However, that study was not included in this present meta-analysis, because of a CEBM level of evidence of only four [8].

The first report on TIP dates to 1994; therefore, including 1990 through 1994 is unnecessary. Excluding these years from the search does not change the findings in this study. Over the years, TIP repair has evolved numerous times as can be seen by following Snodgrass publications [29-32]. Long TIP is not so common, and the use of tunica vaginalis has helped decrease fistula formation. Excluding the oldest repairs, the incidence of the fistula formation and urethral stricture may drop off dramatically. Classifying the findings of the study according to the historical milestones of the TIP technique evolution and demonstrating the outcomes accordingly would be of great interest. This is, however, not feasible due to the small series reported and cannot be done without increasing the bias in the study.

Many factors may influence the repair of hypospadias; therefore, comparison and analysis of literature may not be precise. The analyzed studies did not always document or consistently report on the presence of a ventral curvature, surgeons experience, patients age, previous penile surgery, quality of the penile skin, and configuration of the corpora. The quality of the urethra is an important factor. If there is divergence of the corpus spongiosum, the patient is not a candidate for Mathieu but might be a candidate for TIP. Detailed information is missing in the included reports. It has been documented that a dartos flap reduces the risk of fistula with TIP [33]. Patients or studies that did not include a dartos flap were not excluded due to inconsistent reporting of this in the included publications. A significant complication in TIP is glans dehiscence. Including this complication in the study when evaluating distal hypospadias repair results would add significantly to the paper. However, these data are not available and not consistently reported throughout all the included publications. Therefore, in this meta-analysis, adjustment for confounding factors was not possible, and we could not take full account of the many variables that are related to fistula formation.

Urethral stricture was the second most common complication after hypospadias surgery, with a rate of $2 \%$ after the Mathieu procedure and 5\% after the TIP procedure. Our pooled data estimated a higher rate of urethral stricture for 
TIP than for the Mathieu technique. As in line with fistulas, possible causes for strictures could not be analyzed further because of the lack of information about the confounding factors.

The complications of wound dehiscence and wound infection were excluded from this study. These parameters were not consistently defined or reported in the studies collected for the meta-analysis. Besides, these complications may precede or be a part of the two primary outcomes studied, i.e., fistula and stricture. In the meta-analysis, the secondary outcomes, such as cosmetic results and functional outcomes, were not evaluated. Evaluating these secondary long-term outcomes is necessary in future studies for the comparison of those two techniques and was not in the scope of this study.

In the absence of any functional outcomes, such as uroflows, it is necessary to have some reservation to accept the conclusions of the study, which states that the Mathieu technique, because of the lower risk for postoperative urethral stricture, may be the preferred method for hypospadias. Urinary flow measurements were not consistently reported throughout the literature studied. It is important to note that the long-term result of the Mathieu hypospadias repair is associated with a hairy urethra [34] and abnormal uroflows.

Our study had several limitations. Some critical data were rarely documented, making it impossible to adjust for all possible confounding factors. The significant clinical heterogeneity made our conclusions somewhat conservative, although we used a random effects model. Furthermore, there was a lack of uniform criteria for reporting outcomes and we assumed that the criteria were similar enough to be assessed together. The lack of late follow-up re-stricture is another limitation. Therefore, future studies with complete data and uniform criteria are needed, to identify the best operative intervention for hypospadias. Nevertheless, this study provided valuable information and up-to-date information in this field. The level of evidence on which our review was based was high and our conclusion differed from that of some previous reports [5, 28]. Our results are in favor of the Mathieu over the TIP technique, regarding lowering the risk for urethral stricture.

\section{Risk of bias}

There was potential bias in the review process, including selection bias due to random sequence generation and allocation concealment. Furthermore, performance bias cannot be excluded due to the binding of personnel, and detection bias might be present due to the binding of outcome assessment. Incomplete outcome data (attrition bias), selective reporting (reporting bias), or publication bias was likewise possible.

\section{Conclusions}

Compared with TIP urethroplasty, the Mathieu technique for hypospadias reconstruction was associated with a significantly lower risk for postoperative urethral stricture and may be the preferred method for hypospadias. However, the clinical implications of the results can be discussed because the risk of stricture in both procedures was low. The implications for research are obvious because there had been no studies that provided firm guidelines on the best method for the operative intervention for hypospadias.

Acknowledgements Open access funding provided by Lund University.

Funding No internal or external sources of financial support were provided.

\section{Compliance with ethical standards}

Conflict of interest All authors declare that they have no potential conflicts of interest.

Ethical approval This article does not contain any studies with human participants or animals performed by any of the authors.

Open Access This article is distributed under the terms of the Creative Commons Attribution 4.0 International License (http://creativeco mmons.org/licenses/by/4.0/), which permits unrestricted use, distribution, and reproduction in any medium, provided you give appropriate credit to the original author(s) and the source, provide a link to the Creative Commons license, and indicate if changes were made.

\section{References}

1. Mathieu P (1932) Traitement en un temps de I'hypospadias balanique et juxtabalanique. J Chir 39:481-486

2. Rich MA, Keating MA, Snyder H, Duckett JW (1989) Hinging the urethral plate in hypospadias meatoplasty. J Urol 14:1551-1553

3. Snodgrass W (1994) Tubularized, incised plate urethroplasty for distal hypospadias. J Urol 151:464-465

4. Al-Saied G, Gamal A (2009) Versatility of tubularized incised plate urethroplasty in the management of different types of hypospadias: 5-year experience. Afr J Paediatr Surg 6:88-92

5. Wilkinson DJ, Farrelly P, Kenny SE (2012) Outcomes in distal hypospadias: a systematic review of the Mathieu and tubularized incised plate repairs. J Pediatr Urol 8:307-312

6. PRISMA guidelines. http://www.prisma-statement.org. Accessed 22 Jan 2018

7. Dindo D, Demartines N, Clavien PA (2004) Classification of surgical complications: a new proposal with evaluation in a cohort of 6336 patients and results of a survey. Ann Surg 240:205-213

8. Oxford Centre for Evidence-based Medicine Levels of Evidence (2001) Centre for evidence-based medicine web site. https://www. cebm.net/2009/06/oxford-centre-evidence-based-medicine-level s-evidence-march-2009/. Accessed 22 Jan 2018

9. Mantel N, Haenszel W (1959) Statistical aspects of the analysis of data from retrospective studies of disease. J Natl Cancer Inst 22:719-748 
10. Cochrane community. RevMan information. http://communityc ochrane.org/help/tools-and-software/revman-web. Accessed 28 Jan 2019

11. Aminsharifi A, Taddayun A, Assadolahpoor A et al (2008) Combined use of Mathieu procedure with plate incision for hypospadias repair: a randomized clinical trial. Urology 72:305-308

12. Anwar-ul-haq Akhter N, Nilofer et al (2006) Comparative study of Mathieu and Snodgrass repair for anterior hypospadias. J Ayub Med Coll Abbottabad 18:50-52

13. Bae SH, Lee JN, Kim HT, Chung SK (2014) Urethroplasty by use of turnover flaps (modified Mathieu procedure) for distal hypospadias repair in adolescents: comparison with the tubularized incised plate procedure. Korean J Urol 55:750-755

14. Chrzan R, Dik P, Klijn AJ, de Jong TP (2007) Quality assessment of hypospadias repair with emphasis on techniques used and experience of pediatric urologic surgeons. Urology 70:1148-1152

15. Elganainy EO, Abdelsalam YM, Gadelmoula MM et al (2010) Combined Mathieu and Snodgrass urethroplasty for hypospadias repair: a prospective randomized study. Int J Urol 17:661-665

16. Guo Y, Ma G, Ge Z (2004) Comparison of the Mathieu and the Snodgrass urethroplasty in distal hypospadias repair. Zhonghua Nan Ke Xue 10:916-918 (Chinese)

17. Hamid R, Baba AA, Shera AH (2014) Comparative study of Snodgrass and Mathieu's procedure for primary hypospadias repair. ISRN Urol 27(2014):249765

18. Imamoğlu MA, Bakirtaş H (2003) Comparison of two methods-Mathieu and Snodgrass-in hypospadias repair. Urol Int 71:251-254

19. Karabulut A, Sunay M, Erdem K, Emir L, Erol D (2008) Retrospective analysis of the results obtained by using Mathieu and TIP urethroplasty techniques in recurrent hypospadias repairs. J Pediatr Urol 4:359-363

20. Moradi M, Moradi A, Ghaderpanah F (2005) Comparison of Snodgrass and Mathieu surgical techniques in anterior distal shaft hypospadias repair. Urol J 2:28-31

21. Nezami BG, Mahboubi AH, Tanhaeivash R et al (2010) Hypospadias repair and glans augmentation using a modified Mathieu technique. Pediatr Surg Int 26:299-303

22. Oswald J, Körner I, Riccabona M (2000) Comparison of the perimeatal-based flap (Mathieu) and the tubularized incised-plate urethroplasty (Snodgrass) in primary distal hypospadias. BJU Int $85: 725-727$

23. Oztorun K, Bagbanci S, Dadali M, Emir L, Karabulut A (2017) A retrospective analysis of Mathieu and tip urethroplasty techniques for distal hypospadias repair; a 20-year experience. Arch Esp Urol 70:679-687

24. Samore MA, Malik MA, Iqbal Z (2006) Management of distal hypospadias: Mathieu's repair versus tubularized incised plate urethroplasty. Pak J Surg 22:154-158

25. Ugras MY, Ergin H, Kilic S et al (2006) Factors affecting success in surgery for mid- and distal penile hypospadias: a comparative study of Mathieu and TIPU techniques. Turk Uroloji Dergisi 32:375-380

26. Winberg H, Anderberg M, Arnbjörnsson E (2016) Tubularized incised plate (TIP) repair improves outcome of hypospadias repair. J Surg 4:1-4

27. Yildiz A, Bakan V (2010) Comparison of perimeatal-based flap and tubularized incised plate urethroplasty combined with single- or double-layer dartos flap in distal hypospadias. Urol Int $84: 265-268$

28. Wang F, Xu Y, Zhong H (2013) Systematic review and metaanalysis of studies comparing the perimeatal-based flap and tubularized incised-plate techniques for primary hypospadias repair. Pediatr Surg Int 29:811-821

29. Snodgrass W, Bush N (2016) Primary hypospadias repair techniques: a review of the evidence. Urol Ann 8:403-408

30. Snodgrass W, Bush N (2014) Recent advances in understanding/ management of hypospadias. F1000Prime Rep 6:101

31. Snodgrass WT, Bush N, Cost N (2010) Tubularized incised plate hypospadias repair for distal hypospadias. J Pediatr Urol 6:408-413

32. Snodgrass WT (2008) Utilization of urethral plate in hypospadias surgery. Indian J Urol 24:195-199

33. Liang W, Ji C, Chen Y et al (2016) Surgical repair of mid-shaft hypospadias using a transverse preputial island flap and pedicled dartos flap around urethral orifice. Aesthet Plast Surg 40:535-539

34. Cimador M, Vallasciani S, Manzoni G, Rigamonti W, De Grazia E, Castagnetti M (2013) Failed hypospadias in paediatric patients. Nat Rev Urol 10:657-666

Publisher's Note Springer Nature remains neutral with regard to jurisdictional claims in published maps and institutional affiliations. 